\title{
Variables Affecting Apolipoprotein B Measurements in 3- to 5-Day-Old Babies: A Study of 4491 Neonates
}

\author{
BARBARA L. BLADES, NICHOLAS P. B. DUDMAN, AND DAVID E. L. WILCKEN \\ Department of Cardiovascular Medicine, The University of New South Wales, The Prince Henry Hospital, \\ Sydney, New South Wales, Australia
}

\begin{abstract}
To investigate the feasibility of establishing a neonatal screening program for familial type II hypercholesterolemia, we assayed apolipoprotein B (Apo B), using a radial immunodiffusion assay, in dried blood spot samples from 4491 consecutively born, 3- to 5-day-old neonates. We explored factors influencing levels at the time of sampling and factors associated with the handling of the dried blood spot samples before assay which could affect the assayed value. Assayed Apo B levels were distributed continuously and decreased with increasing delay and temperature of storage of the samples before assay. Female neonates had significantly higher mean Apo B levels than males $(p<0.0001)$, with their respective means \pm SD being $0.246 \pm 0.085 \mathrm{~g} /$ liter $(n=2086)$ and $0.225 \pm$ $0.079 \mathrm{~g} /$ liter of whole blood $(n=2390)$. In both sexes mean Apo B levels were significantly lower in low birth weight $(\leq 2.5 \mathrm{~kg})$ and in low gestational age $(\leq 36 \mathrm{wk})$ neonates. For neonates with birth weight $>2.5 \mathrm{~kg}$ and gestational age more than 36 wk, Apo B levels increased with increasing birth weight and gestational age. Sex, birth weight, and gestational age could account for $5.7 \%$ of the variability of Apo B. After adjustments for these variables, the neonate's age at sampling did not influence Apo B levels significantly. Apo B levels were not affected by different dietary regimens, whether breast-fed, formulafed, or breast-fed with formula complement. We concluded that dried blood spots should be stored frozen if there is to be any delay before assay and that although sex, birth weight, and gestational age contribute only a small amount to the variation in Apo B levels, their influence becomes important when determining a cut-off point for defining abnormal levels. (Pediatr Res 21: 608-614, 1987)
\end{abstract}

\section{Abbreviations}

FHII, familial type II hypercholesterolemia Apo B, apolipoprotein B LDL, low-density lipoprotein VLDL, very low-density lipoprotein $\mathbf{R}^{2}$, coefficient of multiple determination

FHII is an autosomal dominantly inherited condition with an incidence of about one in 500 in the general population. It is characterized by elevated levels of LDL-cholesterol and the pre-

Received October 6, 1986; accepted January 22, 1987.

Correspondence and reprints A/Professor D. E. L. Wilcken, Department of Cardiovascular Medicine, Clinical Sciences Building, The Prince Henry Hospital, Little Bay. N.S.W. 2036, Australia.

Supported by the National Heart Foundation and the Ramaciotti Foundations. mature development of atherosclerosis, with myocardial infarction commonly occurring by the 4 th or 5 th decade of life. FHII is the most frequent inborn error of metabolism with serious consequences, and a neonatal screening program capable of detecting infants with FHII would provide prospects for the prevention of atherosclerosis by identifying young families at risk.

A recent report from the Bogalusa Heart Study (1) showed a strong relationship between antemortem levels of LDL-cholesterol and the development of aortic fatty streaks in childhood. This supports the concept that atherosclerosis begins in childhood and suggests that primary prevention of atherosclerosis should begin early in life. Studies on the effects of cholesterollowering regimens in children have shown them to be safe, with growth and development being unaffected, while cholesterol levels have been reduced to levels shown to be effective in preventing coronary heart disease (2).

The search for an appropriate neonatal screening procedure was initially directed toward the measurement of cholesterol and triglycerides in total cord serum and the various lipoprotein fractions of cord serum (3-6). Apolipoprotein levels have also been measured in cord serum as these may be better genetic markers than lipids for an inherited tendency to develop atherosclerosis (7). However, studies using cord blood have been disappointing due to the influence on foetal lipid metabolism of maternofoetal factors during pregnancy and delivery. These can cause secondary hyperlipidemia at birth and, hence, a high rate of false-positive results $(4,5,8-10)$.

Ongoing neonatal screening programs for phenylketonuria, hypothyroidism, and other disorders require the collection from 3- to 5-day-old neonates of heel-prick blood spot samples onto filter paper. It would be very convenient to be able to use these samples to screen for FHII. Van Biervliet et al. (11), using an immunonephelometric method, showed that it was possible to assay Apo B, a good genetic marker for FHII, in these dried blood spot samples. Van Biervliet et al. (12) had previously found that plasma Apo B levels in neonates rise rapidly during the first 7 days of life then remain constant until day 30 . They concluded that Apo B levels at day 7 represent steady state concentrations and are more meaningful than cord blood levels. Lane and McConathy (13) have recently found similar changes in the first month of life.

If the dried blood spot samples collected routinely from all neonates are to be used for screening for FHII, it is necessary first to determine the factors that influence Apo B levels in the neonate at the time of sampling, and more clearly to define the characteristics of neonatal lipid metabolism and the distribution of Apo B levels. This information is essential before deciding on possible cut-off points to establish levels that could reflect an inborn error of lipid metabolism. Factors associated with the handling of the dried blood spot samples before assay that may 
affect the assayed value also require elucidation. Using a radial immunodiffusion assay for Apo B in dried blood spots on filter paper, developed in our laboratory and described previously (14), we have undertaken the assay of Apo B in a large population of neonates. Our aims were to explore lipid changes in the newborn, with a view to determining the feasibility of establishing a neonatal screening program for FHII.

\section{SUBJECTS, SAMPLES AND METHODS}

We studied 4491 neonates born consecutively between August 1984 and March 1985 at three Sydney metropolitan hospitals. At these hospitals, a heel-prick blood sample was collected onto filter paper (newborn screening cards prepared from filter paper SS2992, Schleicher and Schuell, Keene, NH) from each neonate, generally 4 or 5 days after birth as part of the New South Wales Department of Health Neonatal Screening Program for phenylketonuria, hypothyroidism, cystic fibrosis, and galactosemia. The samples were dried and then sent in batches every 2 to 4 days to The Oliver Latham Laboratory, Sydney, the central screening laboratory.

When all routine screening tests were completed, one blood spot sample from each neonate from these three hospitals was cut from the newborn screening card then sealed in a plastic bag and sent to our laboratory at Prince Henry Hospital. At the beginning of the study, which was during the cooler months, the blood spot samples were not refrigerated until received in our laboratory, where they were then stored in sealed plastic containers at $4^{\circ} \mathrm{C}$ until assayed. During the later hotter months the samples were refrigerated at the Oliver Latham Laboratory before and during transportation to us, and subsequently maintained at $-16^{\circ} \mathrm{C}$ until assayed.

Apo B assay. Apo B levels in the dried blood spots were determined using a radial immunodiffusion assay developed in our laboratory and previously described (14). In this assay, 3$\mathrm{mm}$ discs are punched from the dried blood spots and placed into wells on an agarose gel slab containing antiserum to Apo B. Immediately, $5 \mu \mathrm{l}$ of eluant containing a detergent, Teric (I.C.I., Sydney, Australia), were pipetted onto each disc. After incubation at $23-25^{\circ} \mathrm{C}$ for 7 days, the diameter of the resulting precipitin ring is measured, and the square of the diameter is proportional to the Apo B concentration. The Teric-containing eluant (14) was found not to be stable for more than $1 \mathrm{wk}$ at $4^{\circ}$ $\mathrm{C}$ and thus aqueous Teric was stored at $-16^{\circ} \mathrm{C}$ and diluted in buffer to prepare the eluant just prior to use.

Immunogel slabs were formed by pouring $20 \mathrm{ml}$ of $1 \%$ agarose in $50 \mathrm{mM}$ barbital buffer, $\mathrm{pH} 8.8,10 \mu \mathrm{M}$ EDTA, containing $24.4 \mu \mathrm{l}$ of $18.2 \mathrm{~g} /$ liter titer Behring $\mathrm{LN}$ antiserum to human Apo B (Behringwerke AG, Marburg, West Germany), onto level 12 $\times 12 \mathrm{~cm}$ glass plates. Fifty $3.0-\mathrm{mm}$ diameter wells were punched in each gel just prior to use.

Apo B dried blood spot standards ( 0.125 to $1.25 \mathrm{~g} /$ liter Apo B in whole blood plus a zero standard) were made as previously described (14). The calibrated serum used for the blood spot standards was stored frozen at $-16^{\circ} \mathrm{C}$ in small aliquots with $0.1 \%$ sodium azide and thawed just prior to use

Dried blood spot controls at two different Apo B concentrations (control $1=0.35 \mathrm{~g} /$ liter of blood, control $2=0.65 \mathrm{~g} /$ liter of blood) were prepared using Ortho Bi-level Assayed Lipid Profile Control (Ortho Diagnostic Systems, Raritan, NJ) and stored at $-16^{\circ} \mathrm{C}$ in small aliquots with $0.1 \%$ sodium azide. After thawing, the control sera were mixed with three times washed red cells in a ratio of $1: 1$, then $50-\mu \mathrm{l}$ aliquots were spotted onto newborn screening cards and dried. Both Apo B blood spot standards and controls were stored under the same conditions as the unknowns. The stability of the standardized serum and control sera was monitored regularly by comparing them with Behring Apo B standard serum (Behringwerke AG) by radial immunodiffusion assay.

Throughout the study a total of four different standardized sera was used. Each had been calibrated against Behring Apo B standard serum and during use was regularly checked against this standard serum. New sets of dried blood spot standards and controls were made every 7 to 10 days and were assayed against the previous set of standards to ensure continuity of standard values. To adjust for any slight differences between standardized sera and between sets of dried blood spot standards, all results obtained using a given set of standards were "normalized" using the average value of control 1 obtained using that set of standards.

Normalized Apo B value

$$
=\frac{\text { assayed Apo } \mathrm{B} \text { value } \times 0.35 \mathrm{~g} / \mathrm{liter}}{\text { average value for control } 1}
$$

where $0.35 \mathrm{~g} /$ liter is the "normal" value for control 1 .

Standards, controls, and unknowns were all assayed in duplicate on each gel. Duplicates were positioned three rows apart in case of any irregularity in the gel. Two diameters, perpendicular to each other, were measured for each precipitin ring, and the square of the mean of the two diameters was used to determine the Apo B value from the standard curve.

Data collection and analysis. All samples were assayed blind, only identified by a number, and then data on each neonate's sex, birth weight, gestational age, date of birth, date of sampling, and hospital of birth were recorded (this information was provided on the neonatal screening cards). To explore the effects of different feeding regimens on Apo B levels, dietary information was also obtained in a subgroup of 541 randomly chosen neonates. These neonates were classified as either breast-fed $(n=$ $372)$, formula-fed $(n=59)$, or breast-fed with formula complement $(n=110)$. The formula-fed or formula-complemented infants were fed formulas nutritionally resembling human breast milk. These formulas were "Nan" (Nestle, Sydney, Australia) or "S-26" (Wyeth Pharmaceuticals, Sydney, Australia), or in the case of seven premature infants, "Enfalac Premature Formula" (Mead Johnson, division of Bristol-Myers, Sydney, Australia).

All data analysis was carried out using the UNIX:STATS program $(15,16)$. The results are expressed as mean values \pm $\mathrm{SD}$, and the significance of the differences between group values were assessed by an unpaired $t$ test.

Hierarchical, multiple linear regression analyses (17) were performed with Apo B as the dependent variable. The independent baby-related variables were added to the regression equation in an order determined by examining the variable's correlation with Apo B and the other variables. The independent delay variables were added in chronological order. Where the independent variables of gestational age, birth weight, and baby's age at sampling were categorized before addition to the regression equation, the categories used were as shown in Figures 3 and 4 and Table 1. All categories for a particular variable (expressed as dummy variables) were added to the equation simultaneously.

The square of the multiple regression coefficient is $\mathrm{R}^{2}$ and when multiplied by 100 is a percentage measure of the amount of variation in the dependent variable (Apo B) which can be attributed to the independent variables. The increase in the $R^{2}$ after the addition of a variable to the regression equation is a measure of the variation in Apo B levels which can be uniquely attributed to that variable over and above those variables already entered into the equation.

\section{RESULTS}

Apo $B$ frequency distribution. The frequency distribution of Apo $B$ values obtained from all neonates tested is shown in Figure 1. The mean Apo B was $0.235 \pm 0.083 \mathrm{~g} /$ liter of whole blood $(n=4491)$. The distribution shows a skew to the left (skew $=0.910$ ) with most of the extreme values having high Apo B levels.

Sex differences. Analysis of Apo B values according to sex is shown in Figure 2. There is a significant difference in the mean 
Apo $\mathrm{B}$ values between the sexes, values being higher in the females $(p<0.0001)$. Mean Apo B values for the males and females were $0.225 \pm 0.079 \mathrm{~g} / \mathrm{liter}(n=2390)$ and $0.246 \pm 0.085$ $\mathrm{g} /$ liter $(n=2086)$, respectively.

Influence of birth weight and gestational age on Apo B levels. Males and females were separately grouped into seven birth weight ranges and their group mean Apo B levels studied as a function of birth weight (Fig. 3). For all birth weight groups, the mean Apo B for females was higher than for the males. The majority of both males and females was in the 2.5 to $4.0 \mathrm{~kg}$ range. The mean birth weights of males and females were 3.39 \pm 0.59 and $3.29 \pm 0.56 \mathrm{~kg}$, respectively, $(p<0.005)$. For groups of both sexes with birth weight less than $2.5 \mathrm{~kg}$, the mean Apo B level was lower than the population mean $(p<0.0001)$, and did not change with increasing birth weight within this weight range. Above $2.5 \mathrm{~kg}$, levels increased with increasing birth weight in both sexes (Fig. 3). This increase was particularly marked in females between the 2.0 to 2.5 and 2.5 to $3.0 \mathrm{~kg}$ groups.

When Apo B values were grouped according to gestational age, the pattern for the population was similar to that for birth weight groupings (Fig. 4), largely due to the strong correlation between birth weight and gestational age $(r=0.62, n=4155, p<0.0005)$. Mean Apo B values for females were significantly higher than those for the males in each gestational age group. In both sexes levels remained steady and below the population mean in the

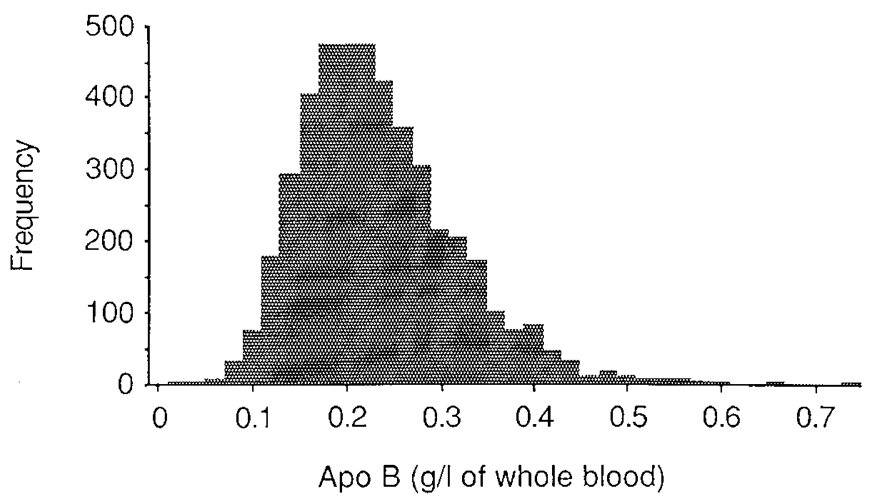

Fig. 1. Frequency distribution of Apo B values in 4491 neonates. Mean Apo $\mathrm{B} \pm \mathrm{SD}=0.235 \pm 0.083 \mathrm{~g} /$ liter of whole blood.

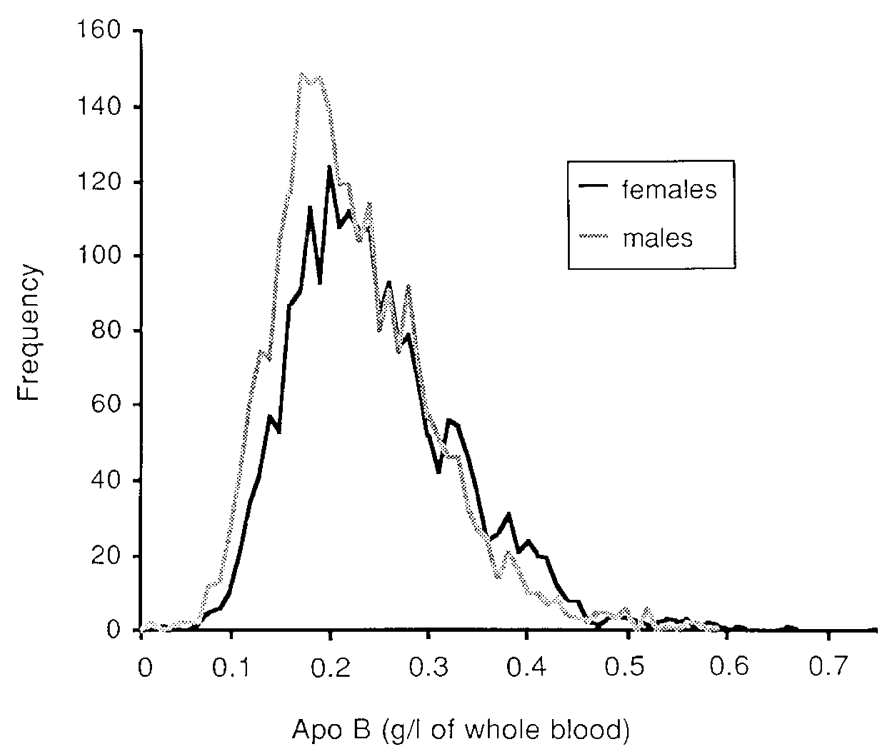

Fig. 2. Frequency distributions of $A$ po $B$ values in males and females (mean Apo $\mathrm{B} \pm \mathrm{SD}=0.225 \pm 0.079 \mathrm{~g} /$ liter of whole blood, $n=2390$, and $0.246 \pm 0.085 \mathrm{~g} /$ liter of whole blood, $n=2086$, respectively).

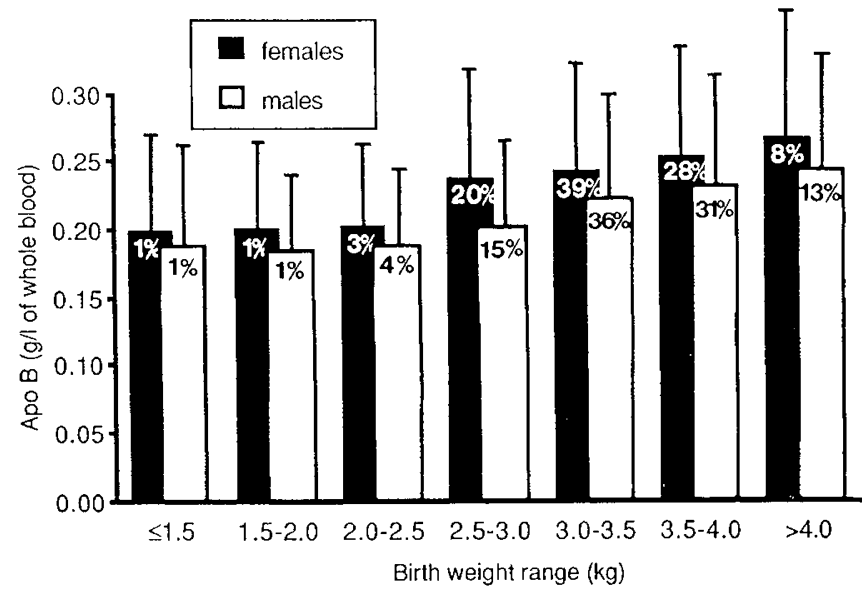

Fig. 3. Mean Apo $\mathrm{B} \pm \mathrm{SD}$ in relation to sex and birth weight range. The percentage (rounded to the nearest whole number) of male or female neonates in each birth weight range is indicated on each column. Apo B levels are higher and increasing with birth weight in groups more than $2.5 \mathrm{~kg}$ containing the majority of the neonates.

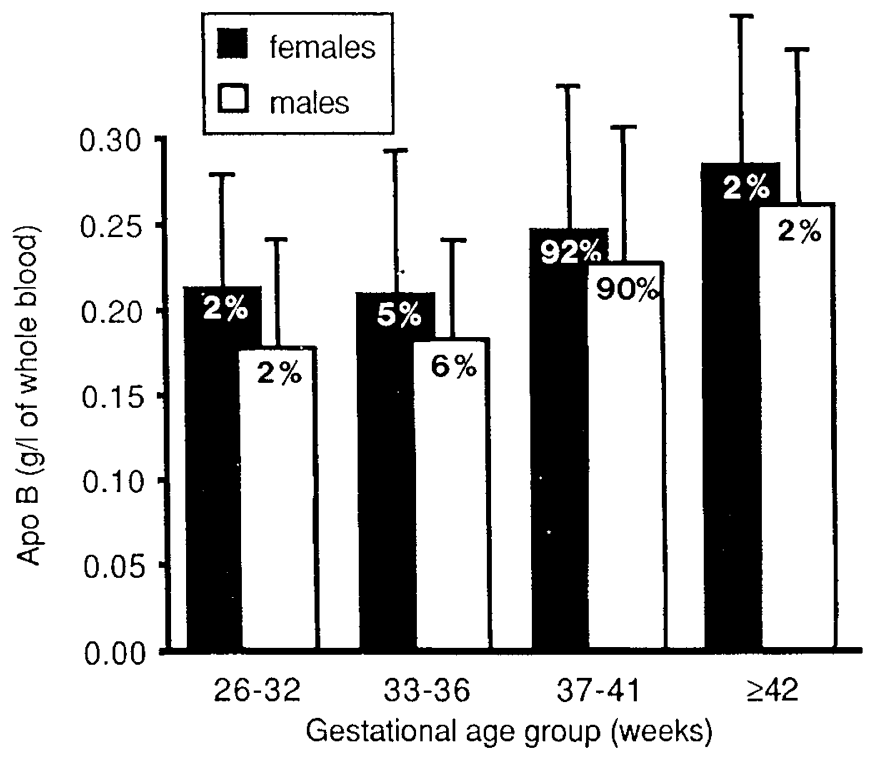

Fig. 4. Mean $A p o B \pm S D$ in relation to sex and gestational age group. The percentage (rounded to nearest whole number) of male or female neonates in each gestational age group is indicated on each column.

less than $37 \mathrm{wk}$ gestational age range and increased progressively above that age.

Influence of the baby's age at sampling on Apo B levels. The majority of neonates was sampled on days 4 or 5 after delivery$49 \%$ on day 4 and $42 \%$ on day 5 . Only $4 \%$ were sampled on day 3 and $2 \%$ on day 6 and the remaining $3 \%$ on or after day 7 .

An increase in Apo B levels was observed from day 3 to day 5 (Table 1). The Apo B levels of neonates sampled on day 5 was significantly higher than for those sampled on day $4(p<0.0001)$, and the mean Apo B value for those sampled on day 3 was lower than for those sampled on day $4(p<0.0001)$. There was a decrease in Apo B levels for those sampled on or after day 6. This decrease, however, was related to these babies having lower mean birth weights and gestational ages than those sampled on days 3,4 , and 5 (Table 1 ).

The quantitative effect of neonate variables on Apo B levels. Hierarchical, multiple linear regression analysis was performed with Apo B as the dependent variable. When the independent variables sex, birth weight, gestational age, and age at sampling 
had been included seriatum in the regression equation, the coefficient of multiple determination was only 0.0581 . Of these variables, birth weight and gestational age were the dominant factors influencing Apo B levels, with respective contributions to the variability of Apo B of 3.11 and $2.59 \%$. If gestational age was inserted into the regression equation before birth weight, their respective contributions remained comparable at 3.57 and $2.13 \%$. Sex differences accounted for only $1.57 \%$ of the variability. Age at sampling was not a significant factor after adjusting for sex, birth weight, and gestational age; it contributed only $0.11 \%$. There were negative correlations between age at sampling and birth weight $(r=-0.21)$ and age at sampling and gestational age $(r=-0.25)$, indicating that babies of low birth weight and/ or low gestational age, tended to be sampled at an older age.

As a representation of practical routine screening, hierarchical multiple linear regression analyses were also carried out with the data for the independent variables categorized according to the birth weight, gestational age, and age at sampling groups shown in Figures 3 and 4, and Table 1, respectively. Sex contributed $1.57 \%$ to the variability at step 1 , and birth weight contributed $2.86 \%$ at step 2 . When added at step 3 gestational age accounted for only $0.62 \%$ of the variability, and age at sampling at step 4 contributed only $0.33 \%$.

Apo $B$ levels in neonates on different dietary regimens. No significant difference was found between the mean Apo B levels of breast-fed $(n=372)$, formula-fed $(n=59)$, and breast-fed with formula complement $(n=110)$ neonates, the mean Apo B levels for each group being $0.235 \pm 0.089 \mathrm{~g} /$ liter, $0.227 \pm 0.096 \mathrm{~g} / \mathrm{liter}$,

Table 1. Effect of neonate's age at sampling on Apo B level, with mean birth wt and gestational age for each age group (mean $\pm S D)$

\begin{tabular}{cccc}
\hline Day of sampling & $\begin{array}{c}\text { Apo B } \\
(\mathrm{g} / \text { liter of blood })\end{array}$ & Birth wt $(\mathrm{kg})$ & $\begin{array}{c}\text { Gestational } \\
\text { age }(\mathrm{wk})\end{array}$ \\
\hline Day 3 $(n=159)$ & $0.225 \pm 0.077$ & $3.44 \pm 0.41$ & $39.5 \pm 1.0$ \\
Day 4 $(n=2045)$ & $0.233 \pm 0.080^{*}$ & $3.38 \pm 0.49^{*}$ & $39.2 \pm 1.4^{*}$ \\
Day 5 $(n=1726)$ & $0.240 \pm 0.086^{*}$ & $3.37 \pm 0.59^{*}$ & $39.1 \pm 1.9^{*}$ \\
Day 6 $(n=89)$ & $0.216 \pm 0.070^{*}$ & $2.86 \pm 0.90^{*}$ & $36.8 \pm 3.9^{*}$ \\
Day 7 $(n=36)$ & $0.201 \pm 0.087$ & $2.63 \pm 0.84$ & $37.1 \pm 3.5$ \\
Day $\geq 8(n=88)$ & $0.214 \pm 0.080$ & $2.46 \pm 0.93$ & $35.6 \pm 4.4$ \\
\hline
\end{tabular}

* Significantly different from previous day, $p<0.0001$ (unpaired $t$ test). and $0.222 \pm 0.072 \mathrm{~g} /$ liter of whole blood, respectively (Table 2). Also, after adjustment for sex, birth weight, gestational age, and age at sampling, feeding regimen was not a significant predictor of Apo B levels in these 541 neonates. A comparison of the mean values for the neonate variables, birth weight, gestational age, and age at sampling for the three dietary regimen groups is given in Table 2. There was no significant difference in the ratio of males to females between the three groups.

Effect of temperature of storage and delay before assay on Apo $B$ levels. To analyze the effects on Apo B levels of the temperature of storage before assay and the effect of delay before assay the samples were divided into two groups: 1) those collected during the cooler months (mean maximum daily temperature $20.0 \pm$ $3.0^{\circ} \mathrm{C}$ ) and not refrigerated until receipt at our laboratory; 2) those collected during the hotter months (mean maximum daily temperature $25.5 \pm 3.2^{\circ} \mathrm{C}$ ) and refrigerated only on receipt at the Oliver Latham Laboratory, and subsequently frozen $\left(-16^{\circ}\right.$ C) on receipt at our laboratory.

The period between sampling and receipt at our laboratory was similar for both groups $(7.0 \pm 2.4$ days for group 1 and 7.1 \pm 2.3 days for group 2). Also for both groups, the period between sampling and assay was similar $(9.7 \pm 3.8$ days for group 1 and $9.1 \pm 3.4$ days for group 2). The period between sampling and refrigeration at Oliver Latham Laboratory for group 2 was $4.9 \pm$ 2.0 days.

There was a decrease in Apo B with increasing delay. Multiple regression analysis revealed that the strongest correlation with Apo B in both groups is with the delay before first being refrigerated ( $r=-0.17$ for group $1, r=-0.21$ for group 2). For both groups the total amount of variability which could be attributed to delay and temperature of storage was less than $5 \%$, with the period between sampling and refrigeration being the most critical (Table 3). Once refrigerated, the period of delay contributed considerably less to the variability, and on freezing (group 2 only) the contribution of delay to the variability decreased further. The variability due to delay before refrigeration was greater during the summer (group 2) than during the winter months (group 1), reflecting the higher temperatures to which the samples were exposed during transport and storage before refrigeration during summer, and as evidenced by the lower mean Apo B for group $2(0.225 \pm 0.082 \mathrm{~g} /$ liter $)$ than for group $1(0.247 \pm 0.090 \mathrm{~g} /$ liter $)$.

\section{DISCUSSION}

In this study we have used the dried blood spot samples, collected as part of ongoing neonatal screening programs, to determine the apolipoprotein B levels in 4491 consecutively born neonates. We have found that the neonate's sex, birth weight, gestational age, and age at sampling influence the Apo B level

Table 2. Comparison of mean Apo B levels and mean values for neonate variables birth weight, gestational age, and age at sampling between breast-fed, formula-fed, and breast-fed with formula complement neonates (mean $\pm S D$, significance of differences between group values was assessed by an unpaired t test)

\begin{tabular}{|c|c|c|c|}
\hline Variable & Breast-fed & Formula-fed & $\begin{array}{c}\text { Breast-fed with } \\
\text { formula complement }\end{array}$ \\
\hline$n$ total & 372 & 59 & 110 \\
\hline male & 200 & 30 & 61 \\
\hline female & 172 & 29 & 49 \\
\hline Apo B (g/liter of whole blood) & $0.235 \pm 0.089$ & $0.227 \pm 0.096$ & $0.222 \pm 0.072$ \\
\hline Birth wt $(\mathrm{kg})$ & $3.44 \pm 0.46$ & $3.36 \pm 0.54$ & $3.28 \pm 0.60^{*}$ \\
\hline Gestational age (wk) & $39.42 \pm 1.22 \dagger$ & $39.07 \pm 1.66^{*}$ & $38.90 \pm 1.71^{*}$ \\
\hline Age at sampling (days) & $4.63 \pm 1.36$ & $4.59 \pm 1.16$ & $4.74 \pm 1.18^{*}$ \\
\hline
\end{tabular}

* Significantly different to breast fed infants, $p<0.0001$.

$\dagger$ Significantly different to formula fed infants, $p<0.0001$. 
Table 3. Hierarchical, multiple linear regression analyses for periods of delay before refrigeration on receipt, and assay (group 1), and refrigeration, freezing on receipt, and assay (group 2) in relation to Apo B levels

\begin{tabular}{|c|c|c|c|c|}
\hline Group & Step & $\begin{array}{c}\text { Variable } \\
\text { (delay before) }\end{array}$ & $\mathbf{R}^{2}$ & $\begin{array}{l}\text { Increase } \\
\text { in } \mathrm{R}^{2 *}\end{array}$ \\
\hline \multirow[t]{2}{*}{1} & 1 & $\begin{array}{c}\text { Refrigeration } \\
\text { on receipt }\end{array}$ & 0.0284 & 0.0284 \\
\hline & 2 & Assay & 0.0322 & 0.0038 \\
\hline \multirow{3}{*}{2} & 1 & Refrigeration & 0.0423 & 0.0423 \\
\hline & 2 & $\begin{array}{l}\text { Freezing on } \\
\text { receipt }\end{array}$ & 0.0459 & 0.0036 \\
\hline & 3 & Assay & 0.0476 & 0.0017 \\
\hline
\end{tabular}

* Increase in $\mathrm{R}^{2}=$ additional variation in Apo B attributable to the variable added at this step in the analysis.

obtained, although age at sampling was only minimally influential. The sample storage temperature and the length of delay before assay also affected the assayed Apo B level, indicating the necessity of standardized handling procedures for the dried blood spot samples before assay. Clearly these factors need to be taken into account in the establishment of a neonatal screening program for FHII. By contrast, Apo B levels were not affected by different dietary regimens, whether breast-fed, formula-fed, or breast-fed with formula complement, all of which had a nutritionally similar composition.

Sex differences. Female neonates had higher Apo B levels than males in all birth weight and gestational age groups, and for those neonates sampled on days 3-6 after birth. None of the previous studies of Apo B levels in 3- to 7-day-old neonates $(11,12,18$ 21) has analyzed the data according to sex. Dolphin et al. (22) reported slightly, although not significantly, higher Apo B levels for females in cord blood, while other studies of Apo B levels in cord blood $(9,23)$ have not commented on any sex differences. In cord blood higher LDL-cholesterol levels in females have been reported $(3,10,24)$. Hardell (10) found sex the dominant factor in the determination of VLDL + LDL cholesterol levels. On the other hand, Ose et al. (4) in a study of cord serum LDLcholesterol and Brewster et al. (7) in a study of cord serum $\beta$ lipoproteins, found no statistically significant difference between the sexes, although the mean values for females were slightly higher than for the males. In a study of serum Apo B levels in Finnish children and adolescents (25), higher levels of serum Apo $B$ were seen in females than males from 3 yr of age until puberty.

It appears that the sex difference we observed for Apo B levels in dried blood spots is part of an overall tracking of Apo B levels from birth to puberty, with females on the average having higher levels than males. As sex is a significantly important predictor of Apo B levels in neonates, sex-related cut-off points will be necessary when screening for FHII.

Birth weight and gestational age. The relationships of increasing Apo B levels with increasing birth weight and gestational age we observed have not been previously reported or considered in previous studies of Apo B levels in 3- to 7-day-old infants (11$13,18,20)$. Our finding that the mean Apo B levels for low birth weight $(\leq 2.5 \mathrm{~kg})$ and for low gestational age ( $\leq 36 \mathrm{wk})$ infants were significantly lower than that of the general population studied contrasts with the findings of Lane and McConathy (9) for cord serum Apo B levels. They reported significantly higher Apo B levels in infants less than $2.0 \mathrm{~kg}$ than for larger babies. Also, for infants less than $2.5 \mathrm{~kg}$, they found higher Apo B levels in those of less than $37 \mathrm{wk}$ gestational age than those of more than 37 wk. Studies of cord serum total and VLDL + LDL cholesterol levels $(4,5,8,9)$ report elevated levels in low birth weight and preterm infants in accordance with Lane and McConathy's (9) findings of elevated Apo B levels in these infants.
It has been proposed (8) that these elevated levels in cord blood are secondary to an increased mobilization of fatty acids near parturition. This could be due to an exaggerated release of catecholamines associated with hypoxia, fetal distress, or adverse intrauterine factors in these preterm babies. The fact that we did not observe elevated Apo B levels in the low birth weight and preterm infants is consistent with these cord blood increases being transient, and by the time of sampling, fatty acid mobilization and metabolism had stabilized. The Apo B level would then reflect the effect on lipid metabolism of the degree of liver and gut maturity appropriate for the infant's gestational age and body weight, interacting with genetic factors.

Although, not surprisingly, there is a good correlation between birth weight and gestational age, possible inaccuracies of up to 4 wk in the documented gestational age makes this a potentially less reliable predictor of Apo B levels than birth weight. When birth weight and gestational age were categorized, after adjustment for sex, birth weight was the best predictor of Apo B. In routine screening therefore, values may need only to be categorized according to sex and birth weight.

Neonatal age at sampling. In our study neonates were normally sampled on days 4 or 5 after birth, with only $4 \%$ being sampled on day 3. Neonates sampled on or after day 6 tended to be of lower birth weight and gestational age than those sampled on days 3 to 5 , suggesting that a delay in sampling was often due to prematurity of the infant or illness. Overrepresentation of premature infants in this group would explain the fall we observed in mean Apo B levels from day 5 to days 6 and 7. However, after adjusting for sex, birth weight, and gestational age, age did not cause a significant variation in Apo B levels.

From our cross-sectional study, we observed a slightly higher mean Apo B level on day 5 than day $4(p<0.0001)$, with the mean level on day 4 slightly higher than on day $3(p<0.0001)$. There are a number of longitudinal studies of neonates comparing cord serum with serum Apo B levels on days 7 and 30 (12, 18 ) or on day 5 (19). These authors observed a dramatic increase of at least $100 \%$ in the $1 \mathrm{st}$ wk of life, with levels then rising only slowly after this time. Mean Apo B levels reported in cord serum $(9,12,18,20,22,23)$ range from 0.20 to $0.28 \mathrm{~g} /$ liter, which would correspond to 0.10 to $0.14 \mathrm{~g} /$ liter in blood. This together with our study indicate that the majority of the increase shown to occur within the 1 st wk of life has occurred by day 3 , and that only small increases can be expected thereafter. The recent findings of Lane and McConathy (13) are in accordance with this.

Cut-off point determination. No bimodality was apparent in the distribution of blood spot Apo B levels in neonates and therefore no natural cut-off point exists to define the boundary between "normal" and "abnormal" neonates. A similar pattern of distribution has been observed for LDL-cholesterol values in both adults (26) and cord blood $(3,8)$.

The lack of a natural cut-off point will necessitate the use of an arbitrary cut-off point such as the 95th percentile to define those neonates with abnormally high Apo B levels. Although quantitatively the variables sex, birth weight, and gestational age have only minor influences on Apo B levels, their influence becomes important in determining an arbitrary cut-off point. In Table 4 the data have been categorized according to sex and birth weight group. It can be seen that if an arbitrary cut-off point is made at the population 95th percentile, a high rate of misclassification would result. The percentage of males and females having Apo B levels greater than this cut-off point was 3.78 and $6.77 \%$, respectively. For both sexes, of those infants with levels above this cut-off point, all infants except one had a birth weight more than $2.5 \mathrm{~kg}$. The percentage of females in the birth weight groups $>2.5-3.0 \mathrm{~kg},>3.0-3.5 \mathrm{~kg},>3.5-4.0 \mathrm{~kg}$, and $>4.0 \mathrm{~kg}$ with Apo B levels above the population 95 th percentile was $5.51,6.64,8.81$, and $9.68 \%$, respectively, while for males the percentages were $0.90,3.33,4.86$, and $7.39 \%$, respectively. Hence, female neonates with birth weights more than $2.5 \mathrm{~kg}$ and 
Table 4. Percentile levels of $A p o B$ in relation to sex and birth wt

\begin{tabular}{|c|c|c|c|c|c|c|c|c|c|}
\hline \multirow[b]{3}{*}{ Sex } & \multirow{3}{*}{$\begin{array}{l}\text { Birth wt } \\
\text { group }\end{array}$} & \multirow[b]{3}{*}{$n$} & \multicolumn{7}{|c|}{ Apo B (g/liter of whole blood) } \\
\hline & & & \multirow[b]{2}{*}{ Mean } & \multicolumn{6}{|c|}{ Percentile } \\
\hline & & & & 25 th & 50 th & 75 th & 90 th & 95th & 98 th \\
\hline $\begin{array}{c}\text { Total } \\
\text { population }\end{array}$ & All & 4491 & 0.235 & 0.18 & 0.22 & 0.28 & 0.34 & 0.38 & 0.43 \\
\hline \multirow[t]{8}{*}{ Female } & All & 2086 & 0.246 & 0.18 & 0.23 & 0.29 & 0.36 & 0.40 & 0.44 \\
\hline & $\leq 1.5 \mathrm{~kg}$ & 23 & 0.199 & 0.15 & 0.20 & 0.24 & 0.28 & 0.29 & 0.36 \\
\hline & $1.5-2.0 \mathrm{~kg}$ & 22 & 0.202 & 0.15 & 0.21 & 0.25 & 0.27 & 0.29 & 0.31 \\
\hline & $2.0-2.5 \mathrm{~kg}$ & 59 & 0.205 & 0.16 & 0.19 & 0.24 & 0.29 & 0.31 & 0.37 \\
\hline & $2.5-3.0 \mathrm{~kg}$ & 399 & 0.239 & 0.18 & 0.23 & 0.29 & 0.34 & 0.39 & 0.42 \\
\hline & $3.0-3.5 \mathrm{~kg}$ & 753 & 0.244 & 0.18 & 0.23 & 0.29 & 0.35 & 0.40 & 0.44 \\
\hline & $3.5-4.0 \mathrm{~kg}$ & 538 & 0.254 & 0.19 & 0.24 & 0.30 & 0.38 & 0.41 & 0.44 \\
\hline & $>4.0 \mathrm{~kg}$ & 155 & 0.268 & 0.20 & 0.25 & 0.33 & 0.38 & 0.44 & 0.51 \\
\hline \multirow[t]{8}{*}{ Male } & All & 2390 & 0.225 & 0.17 & 0.21 & 0.27 & 0.33 & 0.37 & 0.42 \\
\hline & $\leq 1.5 \mathrm{~kg}$ & 28 & 0.190 & 0.15 & 0.18 & 0.20 & 0.26 & 0.32 & 0.37 \\
\hline & $1.5-2.0 \mathrm{~kg}$ & 32 & 0.185 & 0.14 & 0.17 & 0.21 & 0.25 & 0.29 & 0.31 \\
\hline & $2.0-2.5 \mathrm{~kg}$ & 85 & 0.189 & 0.15 & 0.18 & 0.22 & 0.26 & 0.30 & 0.33 \\
\hline & $2.5-3.0 \mathrm{~kg}$ & 335 & 0.204 & 0.16 & 0.19 & 0.25 & 0.29 & 0.32 & 0.34 \\
\hline & $3.0-3.5 \mathrm{~kg}$ & 810 & 0.225 & 0.17 & 0.21 & 0.28 & 0.32 & 0.36 & 0.42 \\
\hline & $3.5-4.0 \mathrm{~kg}$ & 699 & 0.233 & 0.17 & 0.22 & 0.28 & 0.34 & 0.38 & 0.45 \\
\hline & $>4.0 \mathrm{~kg}$ & 284 & 0.245 & 0.18 & 0.23 & 0.29 & 0.35 & 0.41 & 0.48 \\
\hline
\end{tabular}

males with birth weights more than $4.0 \mathrm{~kg}$ would have a disproportionately high rate of "abnormals," while those in other sex/ birth weight groups (particularly males less than $3.0 \mathrm{~kg}$ and females less than $2.5 \mathrm{~kg}$ ) would have a disproportionately high rate of "normals." So ideally, a different cut-off point for each sex/birth weight category would be necessary, although this could be simplified by using larger birth weight groups. For females, possible birth weight groups are $<2.5 \mathrm{~kg}, 2.5-4.0 \mathrm{~kg}$, and $>4.0$ $\mathrm{kg}$, and for males the groups are $\leq 3.0 \mathrm{~kg}$ and $>3.0 \mathrm{~kg}$.

Diet and other variables. Various studies have shown that diet affects the Apo B or LDL-cholesterol levels in older infants (8, 18,27 ), but our data and that of Lane and McConathy (13) establish that in 3- to 5-day-old neonates whether the infant is breast-fed, formula-fed, or breast-fed with formula complement does not significantly influence Apo B levels. It has been well documented that certain perinatal factors do influence lipid levels $(4,5,8,9,22)$. The possible effects of these factors on blood spot Apo B levels in 3- to 5-day-old neonates, which were not studied herein, would best be looked at while controlling for the other variables we have described.

Handling conditions. In agreement with our previous laboratory controlled studies (14), we observed a fall off of Apo B levels in dried blood spots with increasing time and temperature of storage. Even when stored at $4^{\circ} \mathrm{C}$, there was appreciable fall off of $\mathrm{Apo} \mathrm{B}$ levels with time. We conclude that it is best to freeze $\left(-16^{\circ} \mathrm{C}\right)$ samples if there is to be any delay between sampling and assay, if maximal antigenicity of Apo B is to be retained.

The most critical factor in influencing the assayed Apo B level was the delay before refrigeration of samples. In our study, the samples were not at any controlled temperature during this delay and the temperature depending on the prevailing climatic conditions. For this reason, a standardization of the handling procedures for the dried blood spots before receipt at the central testing laboratory would be important when implementing a screening program for FHII using dried blood spots. Current neonatal screening programs do not require dried blood spot samples to be frozen or refrigerated before assay, and practicalities may not allow this. For this reason, hospitals should be encouraged to send the samples to the central laboratory within
1 day of sampling, and on receipt at the central laboratory, the samples should be frozen or assayed immediately.

Acknowledgments. The authors thank Calbiochem-Behring Australia Pty. Ltd., for practical support, and The Oliver Latham Laboratory, in particular Dr. Bridget Wilcken, for making available the neonatal screening samples. We acknowledge the cooperation of the Royal Hospital for Women, Paddington, The St. George Hospital, Kogarah, and The Sutherland Hospital, Caringbah, in allowing us to screen babies born at their institutions. We particularly thank Ms. Susan Connellan for technical assistance. We also thank Dusan Hadzi-Pavlovic for advice on statistical analysis.

\section{REFERENCES}

1. Newman WP, Freedman DS, Voors AW, Gard PD, Srinivasan SR, Cresanta JL, Williamson GD, Webber LS, Berenson GS 1986 Relation of serum lipoprotein levels and systolic blood pressure to early atherosclerosis. The Bogalusa Heart Study. N Engl J Med 314:138-144

2. Glueck CJ 1986 Pediatric primary prevention of atherosclerosis. N Engl J Med 314:175-177

3. Hardell LI 1981 Serum lipids and lipoproteins at birth based on a study of 2815 newborn infants. I. Concentration and distribution of triglycerides and cholesterol. Acta Paediatr Scand [Suppl] 285:5-10

4. Ose L, Iden A, Bakke T, Aarskog D 1975 Neonatal screening for hyperlipidemia. Postgrad Med J 51:88-92

5. Andersen GE, Lous P, Friis-Hansen B 1979 Hyperlipoproteinemia in newborn infants. A study of 1025 families. Acta Paediatr Scand 68:683-690

6. Boulton TJC, Craig IH, Hill G 1979 Screening of cord blood low-densitylipoprotein cholesterol in the diagnosis of familial hypercholesterolaemia: a study of 2000 infants. Acta Paediatr Scand 68:363-370

7. Brewster TG, Waite DJ, Hudson GA 1982 Quantitation of $\beta$-lipoprotein in cord serum by rate nephelometric immunoassay: a potential screening test for familial hypercholesterolemia. Clin Chem 28:1192-1196

8. Boulton TJC 1979 Fetal, and maternal and intrapartum factors and their effects on cord serum cholesterol and triglyceride. Aust NZ J Med 9:57-62

9. Lane DM, McConathy WJ 1983 Factors affecting the lipid and apolipoprotein levels of cord sera. Pediatr Res 17:83-91

10. Hardell LI 1981 Serum lipids and lipoproteins at birth based on a study of 2815 newborn infants. II. Relations between maternofoetal factors and the concentration of triglycerides and cholesterol. Acta Paediatr Scand [Suppl] 285:11-20

11. Van Biervliet JP, Vinaimont N, Caster H, Rosseneu M, Belpaire F 1982 A screening procedure for dyslipoproteinemia in the newborn. Apoprotein quantitation on dried blood spots. Clin Chim Acta 120:191-200

12. Van Biervliet JP, Vercaemst R, De Keersgieter W, Vinaimont N, Caster $\mathbf{H}$, 
Rosseneu M 1980 Evolution of lipoprotein patterns in newborns. Acta Paediatr Scand 69:593-596

13. Lane DM, McConathy WJ 1986 Changes in the serum lipids and apolipoproteins in the first four weeks of life. Pediatr Res 20:332-337

14. Dudman NPD, Blades BL, Wilcken DEL, Aitken JM 1985 Radial immunodiffusion assay of apolipoprotein B in blood dried on filter paper-a potential screening method for familial type II hypercholesterolaemia. Clin Chim Acta 149:117-127

15. Perlman G 1980 Data analysis programs for the UNIX operating system. Behav Res Methods Instr 12:554-558

16. Perlman G 1982 UNIX/STAT: Compact data analysis programs for UNIX. In: Proceedings of the 1982 Summer USENIX Conference USENIX, Boston

17. Cohen J, Cohen P 1983 Applied Multiple Regression/Correlation Analysis for the Behavioural Sciences, 2nd ed. Laurence Erlbaum, Hillsdale, NJ

18. Van Biervliet JP, Vinaimont N, Caster H, Vercaemst R, Rosseneu M 1981 Plasma apoprotein and lipid patterns in newborns: influence of nutritional factors. Acta Paediatr Scand 70:851-856

19. Vladutiu GD, Glueck CJ, Schultz MT, McNeely S, Guthrie R $1980 \beta$ Lipoprotein quantitation in cord blood spotted on filter paper: a screening test. Clin Chem 26:1285-1290

20. Strobl W, Widhalm K, Kostner G, Pollak A 1983 Serum apolipoproteins and lipoprotein (a) during the first week of life. Acta Paediatr Scand 72:505-509
21. Koffigan M, Fruchart JC, Dhondt JL, Moschetto Y, Farriaux JP 1982 Apolipoprotein B measurement in blood spotted on paper. Ric Clin Lab 12:169172

22. Dolphin PJ, Breckenridge WC, Dolphin MA, Tan MH 1984 The lipoproteins of human umbilical cord blood. Apolipoprotein and lipid levels. Atherosclerosis 51:109-122

23. Srinivasan SR, Sharma C, Foster TA, Berenson GS 1982 Longitudinal changes of serum lipid and apo B levels in a newborn-infant cohort. Metabolism 31:167-171

24. Carlson LA, Hardell LI 1977 Sex differences in serum lipids and lipoproteins at birth. Eur $\mathrm{J}$ Clin Invest 7:133-135

25. Solakivi-Jaakkola T, Nikkari T, Viikari J, Akerblom HK, Rasanen L, Uhari M, Dahl M, Lahde PL, Pesonen E, Pietikainen M, Suoninen P 1985 Atherosclerosis precursors in Finnish children and adolescents. VI. Serum apolipoproteins A-1 and B. Acta Paediatr Scand [Suppl] 318:119-125

26. LaRosa JC, Chambless LE, Criqui MH, Frantz ID, Glueck CJ, Heiss G, Morrison JA 1986 Patterns of dyslipoproteinemia in selected North American populations. The Lipid Research Clinics Program Prevalence Study. Circulation 73:1-12

27. Glueck CJ, Tsang RC 1972 Pediatric familial type II hyperlipoproteinemia: effects of diet on plasma cholesterol in the first year of life. Am J Clin Nutr 25:224-230 